Supporting Information for:

\title{
Mesoporous Poly(benzimidazole) Networks via Solvent Mediated Templating of Hard Spheres
}

by

Jens Weber, Markus Antonietti and Arne Thomas*
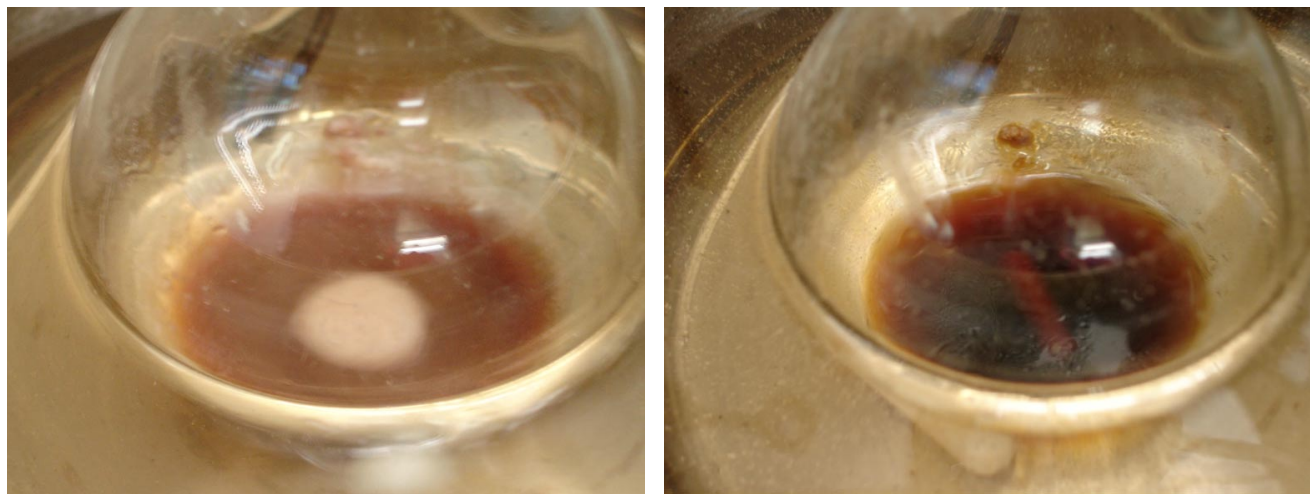

Figure S1: Photographs of the reaction mixture (monomers / silica nanoparticles / DMF) at room temperature and $120^{\circ} \mathrm{C}$, respectively.
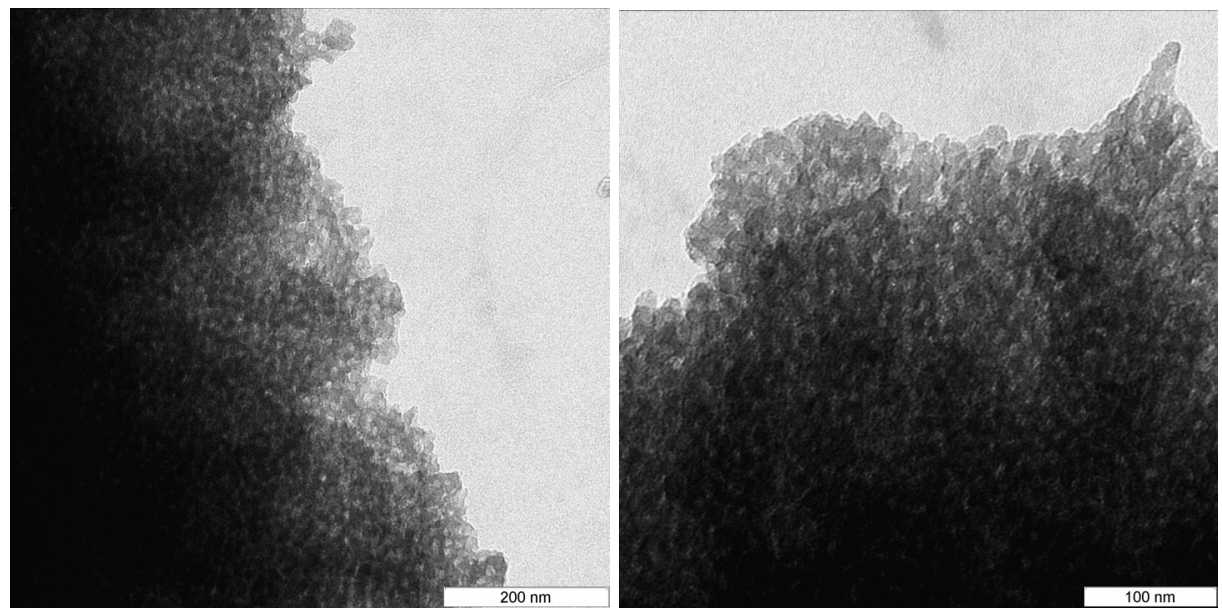

Figure S2: TEM micrographs of bulk mpPBI-3 


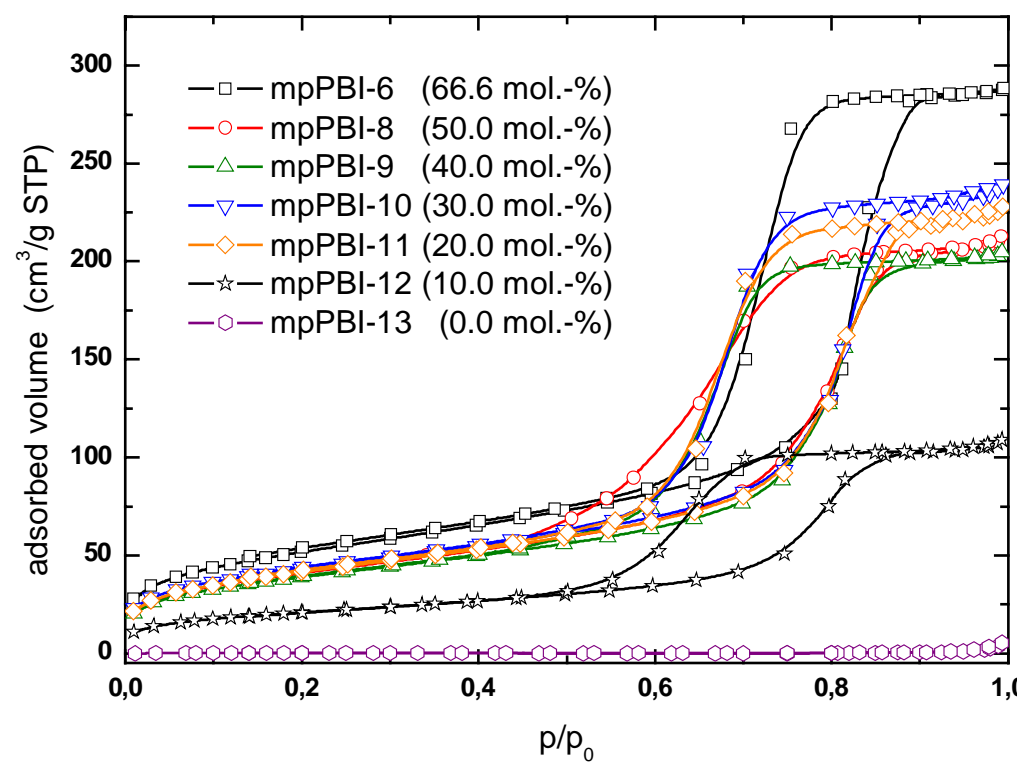

Figure S3: Nitrogen sorption isotherms for samples with varying cross-linking density

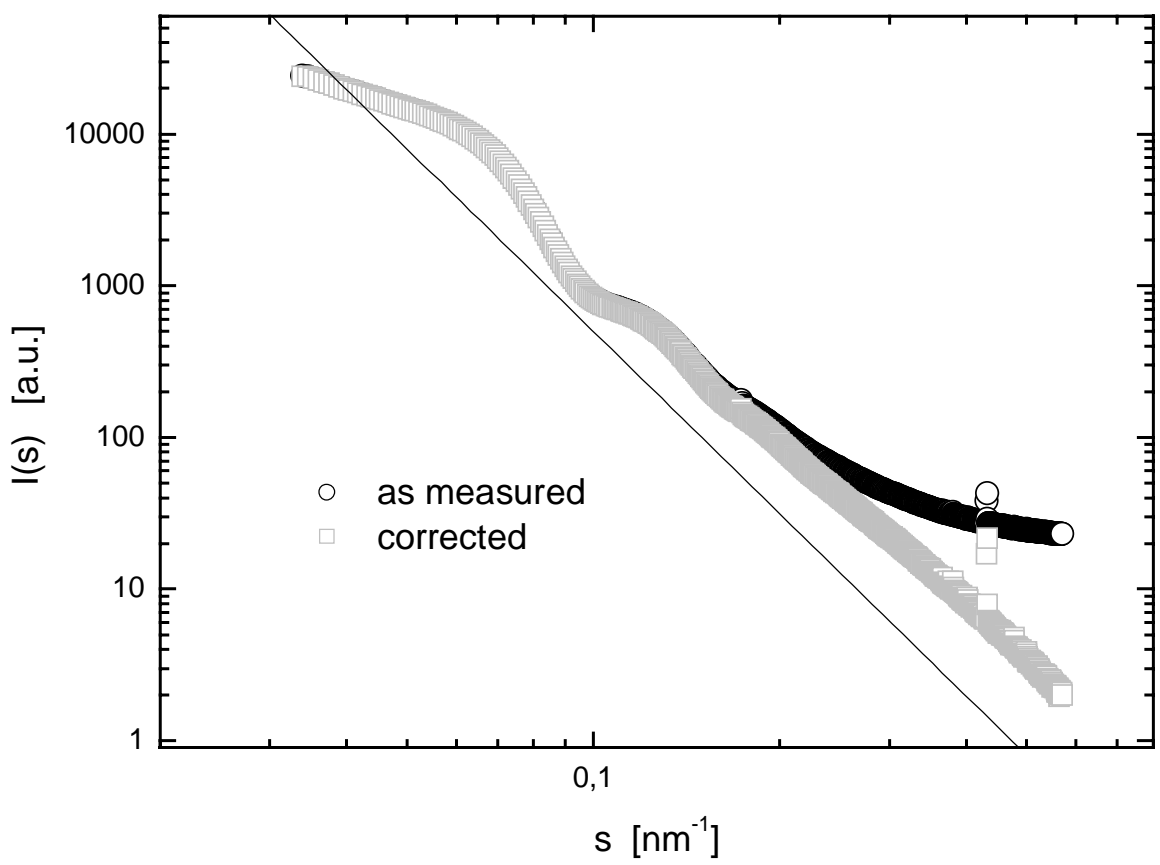

Figure S4: Scattering curve of a mesoporous PBI as measured and corrected for 3D electron density fluctuations as described in Ref. 38 
Table S1: Numerical results of the SAXS experiments obtained by different approaches: Values obtained by the classical approach $^{36}$ (a) and the parametrisation approach ${ }^{37}$ (b).

\begin{tabular}{ccccc} 
Sample & $\boldsymbol{l}_{\boldsymbol{p}}{ }^{\boldsymbol{a})}[\mathbf{n m}]$ & $\mathbf{S}^{\boldsymbol{a})}\left[\mathbf{m}^{2} / \mathbf{g}\right]$ & $\boldsymbol{l}_{\boldsymbol{p}}{ }^{\boldsymbol{b})}[\mathbf{n m}]$ & $\mathbf{S}^{\boldsymbol{b})}\left[\mathbf{m}^{2} / \mathbf{g}\right]$ \\
\hline mpPBI-1 & 6.39 & 67.5 & 6.41 & 67 \\
mpPBI-2 & 6.19 & 76.5 & 6.66 & 71 \\
mpPBI-3 & 7.17 & 107 & 7.08 & 108 \\
mpPBI-4 & 7.31 & 122 & 7.29 & 127 \\
mpPBI-5 & 7.46 & 113 & 7.29 & 116 \\
mpPBI-6 & 7.00 & 163 & 6.99 & 163 \\
mpPBI-7 & 5.93 & 128 & 5.84 & 130 \\
mpPBI-8 & 6.02 & 155 & 6.27 & 149 \\
mpPBI-9 & 6.87 & 132 & 6.83 & 133 \\
mpPBI-10 & 6.98 & 5 & 8.97 & 4 \\
mpPBI-11 & 6.02 & 168 & 6.3 & 161 \\
mpPBI-12 & 6.32 & 155 & 6.57 & 149 \\
mpPBI-13 & 7.53 & 74 & 7.37 & 76
\end{tabular}

